\title{
Susceptibility breakpoint for Danofloxacin against swine Escherichia coli
}

\author{
Yuqi Yang ${ }^{1}$, Yixin Zhang ${ }^{1}$, Jiarui Li ${ }^{1}$, Ping Cheng ${ }^{1}$, Tianshi Xiao ${ }^{1}$, Ishfaq Muhammad ${ }^{1}$, Hongxiao Yu', \\ Ruimeng Liu ${ }^{1}$ and Xiuying Zhang ${ }^{1,2^{*}}$ (D)
}

\begin{abstract}
Background: Improper use of antimicrobials results in poor treatment and severe bacterial resistance. Breakpoints are routinely used in the clinical laboratory setting to guide clinical decision making. Therefore, the objective of this study was to establish antimicrobial susceptibility breakpoints for danofloxacin against Escherichia coli (E.coli), which is an important pathogen of digestive tract infections.
\end{abstract}

Results: The minimum inhibitory concentrations (MICs) of 1233 E. coli isolates were determined by the microdilution broth method in accordance with the guidelines in Clinical and Laboratory Standards Institute (CLSI) document M07-A9. The wild type (WT) distribution or epidemiologic cutoff value (ECV) was set at $8 \mu \mathrm{g} / \mathrm{mL}$ with statistical analysis. Plasma drug concentration data were used to establish pharmacokinetic (PK) model in swine. The in vitro time kill test in our study demonstrated that danofloxacin have concentration dependent activity against $E$. coli. The PK data indicated that danofloxacin concentration in plasma was rapidly increased to peak levels at $0.97 \mathrm{~h}$ and remained detectable until $48 \mathrm{~h}$ after drug administration. The pharmacodynamic cutoff (COPD) was determined as $0.03 \mu \mathrm{g} / \mathrm{mL}$ using Monte Carlo simulation. To the best of our knowledge, this is the first study to establish the $\mathrm{ECV}$ and $\mathrm{CO}_{\mathrm{PD}}$ of danofloxacin against E.coli with statistical method.

Conclusions: Compared to the COPD of danofloxacin against E.coli $(0.03 \mu \mathrm{g} / \mathrm{mL})$, the ECV for E.coli seemed reasonable to be used as the final breakpoint of danofloxacin against E.coli in pigs. Therefore, the ECV (MIC $\leq 8 \mu \mathrm{g} / \mathrm{mL})$ was finally selected as the optimum danofloxacin susceptibility breakpoint for swine E.coli. In summary, this study provides a criterion for susceptibility testing and improves prudent use of danofloxacin for protecting public health.

Keywords: Danofloxacin, Escherichia coli, ECV, COPD, Monte Carlo simulation

\section{Background}

Escherichia coli (E.coli) are a common member of microflora of the gastrointestinal tract of animals and humans. Pathogenic E. coli associated with gastrointestinal disorders have been divided into eight pathotypes based on their virulence profiles: enteropathogenic E. coli (EPEC); enterohaemorrhagic $E$. coli (EHEC); enterotoxigenic E. coli (ETEC); enteroinvasive $E$. coli (EIEC); enteroaggregative $E$. coli (EAEC); diffusely adherent E. coli (DAEC); adherent invasive E. coli (AIEC); and shiga toxin-producing

\footnotetext{
* Correspondence: zhangxiuying@neau.edu.cn

${ }^{1}$ Heilongjiang Key Laboratory for Animal Disease Control and Pharmaceutical Development. Faculty of Basic Veterinary Science, College of Veterinary Medicine, Northeast Agricultural University, 600 Changjiang Road, Xiangfang District, Harbin, People's Republic of China

${ }^{2}$ Department of Basic Veterinary Science, College of Veterinary Medicine, Northeast Agricultural University, Harbin, Heilongjiang 150030, People's Republic of China
}

enteroaggregative E. coli (STEC) [1]. Among them, ETEC infects both humans and several species of farm animals such as pigs. In humans, ETEC is the main cause of bacterial diarrhea in adults and children in developing countries and also a leading cause of traveler's diarrhea [2, 3]. In pigs, enteric diseases due to strains of ETEC are the most commonly occurring form of colibacillosis including neonatal diarrhoea and postweaning diarrhoea (PWD), which result in significant economic losses due to mortality, morbidity, reduced growth rate and cost of medication [4].

Quinolones, which trap DNA gyrase or topoisomerase IV to form reversible drug enzyme DNA cleavage complexes, to cause bacteriostasis, have a high bioavailability, good tissue penetration, long half-lives, high efficacy, and low incidence of adverse effects. Because of these characteristics, they are widely used against several respiratory and gastrointestinal infections in both humans

(c) The Author(s). 2019 Open Access This article is distributed under the terms of the Creative Commons Attribution 4.0 International License (http://creativecommons.org/licenses/by/4.0/), which permits unrestricted use, distribution, and reproduction in any medium, provided you give appropriate credit to the original author(s) and the source, provide a link to the Creative Commons license, and indicate if changes were made. The Creative Commons Public Domain Dedication waiver (http://creativecommons.org/publicdomain/zero/1.0/) applies to the data made available in this article, unless otherwise stated. 
and animals $[5,6]$. The antimicrobial treatment of traveler's diarrhea has changed over the years because of the increasing resistance of ETEC to common antibiotics. So far, fluoroquinolones have been shown to be an effective therapy for ETEC traveler's diarrhea [7, 8]. Danofloxacin (DANO), a third generation fluoroquinolone antimicrobial drug with rapid bactericidal activity, is often employed to treat colibacillosis in swine via oral or intramuscular administration [9, 10]. However, their extensive use has also serious non-desirable impacts and represents a public health danger. For example, it may stimulate the emergence of zoonotic quinolone-resistant E.coli in the food-producing animals, which can ultimately be transmitted to the human by direct contact or through the food chain [11, 12]. Plasmid-mediated fluoroquinolone resistance genes (qnrS and aac (6 $\left.6^{\prime}\right)$-Ib-cr) are detected in both patients and pigs in Shandong, China, and these resistance genes can be transmitted horizontally [13].

Improper use of antibiotics results in severe bacterial resistance. Breakpoints are routinely used in the clinical laboratory setting to guide clinical decision making. A combination of MIC values, pharmacokinetic/pharmacodynamic relationship and clinical outcome data are needed to set breakpoints [14]. However, this kind of data needed for breakpoint determination is so difficult and expensive to generate. Epidemiological cutoff values (ECVs) are the useful tools for laboratories conducting susceptibility testing and for clinicians treating infections. Those tools also offer alternative ways for monitoring the emergence of drug resistance in any given bacterial species [14]. ECVs establishment using the CLSI method must include MIC distributions $(\geq 100$
MIC results per species and Antibacterial agent) from multiple $(\geq 3)$ independent laboratories $[15,16]$. Previous studies demonstrated that a statistical method was a professional and scientific method which has been adopted by the CLSI as a standard method for ECV determination $[17,18]$. Pharmacodynamic cutoff $\left(\mathrm{CO}_{\mathrm{PD}}\right)$ is associated with clinical efficacy, as both WT values and $\mathrm{PK} / \mathrm{PD}$ data are used to setting $\mathrm{CO}_{\mathrm{PD}}$ without clinical cutoff values [19]. The $\mathrm{CO}_{\mathrm{PD}}$ was defined as the MIC at which the probability of target attainment (PTA) was $\geq 90 \%$ [20]. Monte Carlo simulation has been employed to assess the probability of attaining the desired AUC:MIC ratio, and it provides a means by which probability outcomes, such as achieving the PK/PD target, can be attained without the rigor, time, and expense of clinical trials $[21,22]$.

The purposes of the present study were (i) to develop ECV of DANO against E.coli using a statistical method and (ii) to establish DANO $\mathrm{CO}_{\mathrm{PD}}$ for E.coli based on Monte Carlo simulation.

\section{Results \\ Isolates}

From July 2014 to March 2017, a total of 861 E.coli isolates were identified from $864 \mathrm{rectal} /$ cloacal swabs of pigs. Isolates were collected from Heilongjiang $(n=296)$, Jilin $(n=151)$, Liaoning $(n=238)$, Henan $(n=97)$, Shandong $(n=30)$, Hubei $(n=20)$, and Yunnan $(n=29)$ provinces of China.

\section{Antibacterial susceptibility testing}

As shown in the primitive DANO MIC distribution in Fig. 1, MICs for DANO against 1233 E.coli isolates (861

\section{Danofloxacin}

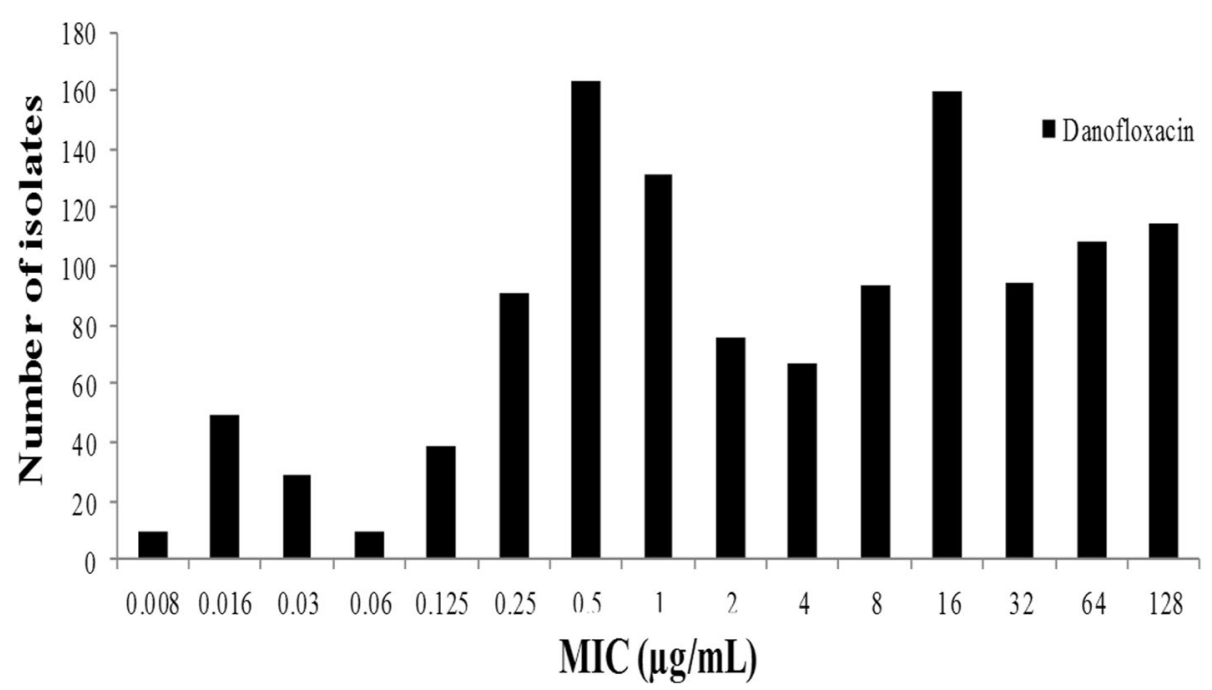

Fig. 1 Primary MIC distribution of danofloxacin against 1233 E.coli isolates 
isolated, 372 donated) were in the range of 0.008 to $128 \mu \mathrm{g} / \mathrm{mL}$. The percentages at each $\operatorname{MIC}(0.008,0.016$, $0.03,0.06,0.03,0.25,0.5,1,2,4,8,16,32,64$ and $128 \mu \mathrm{g} / \mathrm{mL}$ ) were $0.73,3.97,2.35,0.73,3.16,7.38,13.22$, $10.62,6.16,5.43,7.54,12.98,7.62,8.76$ and $9.33 \%$. The $\mathrm{MIC}_{50}$ and $\mathrm{MIC}_{90}$ were 4 and $128 \mu \mathrm{g} / \mathrm{mL}$, respectively.

\section{Epidemiological cut-off values}

The MIC distribution $(0.008-128 \mu \mathrm{g} / \mathrm{mL})$ for DANO was statistically consistent with a normal distribution because the skewness $(-0.321)$ and kurtosis $(-0.731)$ were negative. As the normal (Gaussian) distribution is widely accepted, non-linear regression curve fitting of cumulative $\log _{2}$ MIC data was selected as the preferred method for determining the means and standard deviations of MIC distributions. The procedure involved fitting the initial subset and generating estimates for the number of strains in the subset, the mean and the standard deviation (in log). This procedure was repeated by adding to the previous subset each successive column to create the next subset, and repeating the curve-fitting until it was clear that there was a subset where the absolute difference between the true and estimated number of isolates was a minimum. As shown in Table 1 and Fig. 2, the seven subsets examined showed that the subset 'MIC = $8 \mu \mathrm{g} / \mathrm{mL}$ ' gave the minimum difference. As a result, the ECV was defined as $8 \mu \mathrm{g} / \mathrm{mL}$.

\section{In vitro time-kill studies}

As presented in Fig. 3, the concentrations (1/4 MIC and $1 / 2$ MIC) below the MIC of DANO can hardly inhibited the growth of E. coli JLP95. Similarly, the bacteriostatic effects of $1 \mathrm{MIC}$ and $2 \mathrm{MIC}$ of DANO are not obvious. However, the antibacterial or bactericidal effects are gradually enhanced when DANO concentrations were at least 4 times higher than MIC. Therefore, the in vitro time-kill test shows that efficacy of DANO against E.coli is concentration dependent.

\section{Pharmacokinetic characteristics of DANO in plasma}

There are no adverse reactions after intramuscular injection of DANO. The concentration of plasma DANO was decreased below LOQ after $72 \mathrm{~h}$. The concentration-time curves are presented in Fig. 4. According to MAICE, the plasma data were best fitted to a two-compartmental PK model for all six pigs. Pharmacokinetic parameters are shown in Table 2, the time to reach to maximum drug concentration $\left(\mathrm{T}_{\max }\right)$, the peak drug concentration $\left(\mathrm{C}_{\max }\right)$, and the area under the curve by $24 \mathrm{~h}\left(\mathrm{AUC}_{0-24}\right)$ were $0.97 \pm 0.08 \mathrm{~h}, 0.76 \pm 0.08 \mu \mathrm{g} / \mathrm{mL}$, and $5.25 \pm 1.35 \mathrm{~h} \cdot \mu \mathrm{g} / \mathrm{ml}$, respectively.

\section{Monte Carlo analysis}

Results of a 10,000- Monte Carlo simulation for DANO based on $\mathrm{MIC}$ and $\mathrm{AUC}_{0-24}$, the probability of achieving various AUC: MIC ratios at breakpoints of $0.03 \mu \mathrm{g} / \mathrm{mL}$ are presented in Fig. 5. The red bars represent the number of simulated with AUC: MIC ratios < 125, whereas the gray bars represent with AUC: MIC ratios of $\geq 125$. The probability of DANO attaining an AUC: MIC ratio of at least 125 is $92.25 \%$. Therefore, the $\mathrm{CO}_{\mathrm{PD}}$ was defined at $0.03 \mu \mathrm{g} / \mathrm{mL}$. The following statistical parameters describe the DANO AUC: MIC probability distribution: mean 188.84, median 188.86, SD 44.91, variance 2017.05, skewness - 0.024, kurtosis 3.03, coeff. of variability 0.24 , minimum range 10.42 , maximum range 345.06 , and mean std. error 0.45 .

\section{Discussion}

DANO is a fluoroquinolone antibacterial drug that was developed specifically for veterinary use [23]. However, the resistant E.coli isolates are emerging quickly with the use of these drugs [24]. A total of $1737 \mathrm{E}$. coli isolates collected from the United States, Canada, Belgium, France, Germany, Italy, the Netherlands, Spain, the United Kingdom, Japan, and South Africa showed a high degree of susceptibility to DANO, more than $99.3 \%$ of

Table 1 Optimum non-linear least squares regression fitting of pooled MICs ( $\mathrm{mg} / \mathrm{mL}$ ) for danafloxacin and E.coli

\begin{tabular}{|c|c|c|c|c|c|c|c|c|c|c|c|c|c|c|}
\hline \multirow{2}{*}{$\begin{array}{l}\text { Subset } \\
\text { fitted }\end{array}$} & \multicolumn{6}{|c|}{ Number of isolates } & \multicolumn{4}{|c|}{ Mean MIC $\left(\log _{2}\right)$} & \multicolumn{4}{|c|}{ Standard deviation $\left(\log _{2}\right)$} \\
\hline & $\overline{\text { TRUE }}$ & Est. & Diff. & ASE & Est./ASE & $95 \% \mathrm{Clb}$ & $\overline{\text { Est. }}$ & ASE & Est./ASE & $95 \% \mathrm{Cl}^{\mathrm{a}}$ & $\overline{\text { Est. }}$ & ASE & Est./ASE & $95 \% \mathrm{Cl}^{\mathrm{b}}$ \\
\hline$\leq 128$ & 1233.00 & 1417.00 & 184.00 & 106.60 & 13.29 & 1185 to 1650 & 2.22 & 0.54 & 4.12 & 1.046 to 3.394 & 4.63 & 0.42 & 11.01 & 3.711 to 5.544 \\
\hline$\leq 64$ & 1118.00 & 1293.00 & 175.00 & 108.50 & 11.92 & 1054 to 1532 & 1.64 & 0.55 & 2.95 & 0.4138 to 2.856 & 4.27 & 0.43 & 9.90 & 3.324 to 5.224 \\
\hline$\leq 32$ & 1010.00 & 1174.00 & 164.00 & 114.30 & 10.27 & 919.5 to 1429 & 1.07 & 0.59 & 1.81 & -0.2443 to 2.385 & 3.93 & 0.46 & 8.64 & 2.918 to 4.947 \\
\hline$\leq 16$ & 916.00 & 1040.00 & 124.00 & 113.90 & 9.13 & 782.2 to 1298 & 0.42 & 0.60 & 0.70 & -0.9379 to 1.780 & 3.53 & 0.47 & 7.53 & 2.471 to 4.594 \\
\hline$\leq 8 b$ & 756.00 & 829.80 & 73.80 & 63.56 & 13.06 & $\begin{array}{l}683.2 \text { to } \\
976.3\end{array}$ & -0.63 & 0.36 & -1.75 & $\begin{array}{l}-1.469 \text { to } \\
0.2008\end{array}$ & 2.81 & 0.33 & 8.54 & $\begin{array}{l}2.051 \text { to } \\
3.569\end{array}$ \\
\hline$\leq 4$ & 663.00 & 786.90 & 123.90 & 93.92 & 8.38 & 564.8 to 1009 & -0.85 & 0.51 & -1.68 & -2.041 to 0.3476 & 2.66 & 0.41 & 6.43 & 1.679 to 3.634 \\
\hline$\leq 2$ & 596.00 & 980.00 & 384.00 & 353.30 & 2.77 & 115.5 to 1844 & -0.01 & 1.47 & -0.01 & -3.611 to 3.590 & 3.12 & 0.79 & 3.95 & 1.184 to 5.052 \\
\hline
\end{tabular}




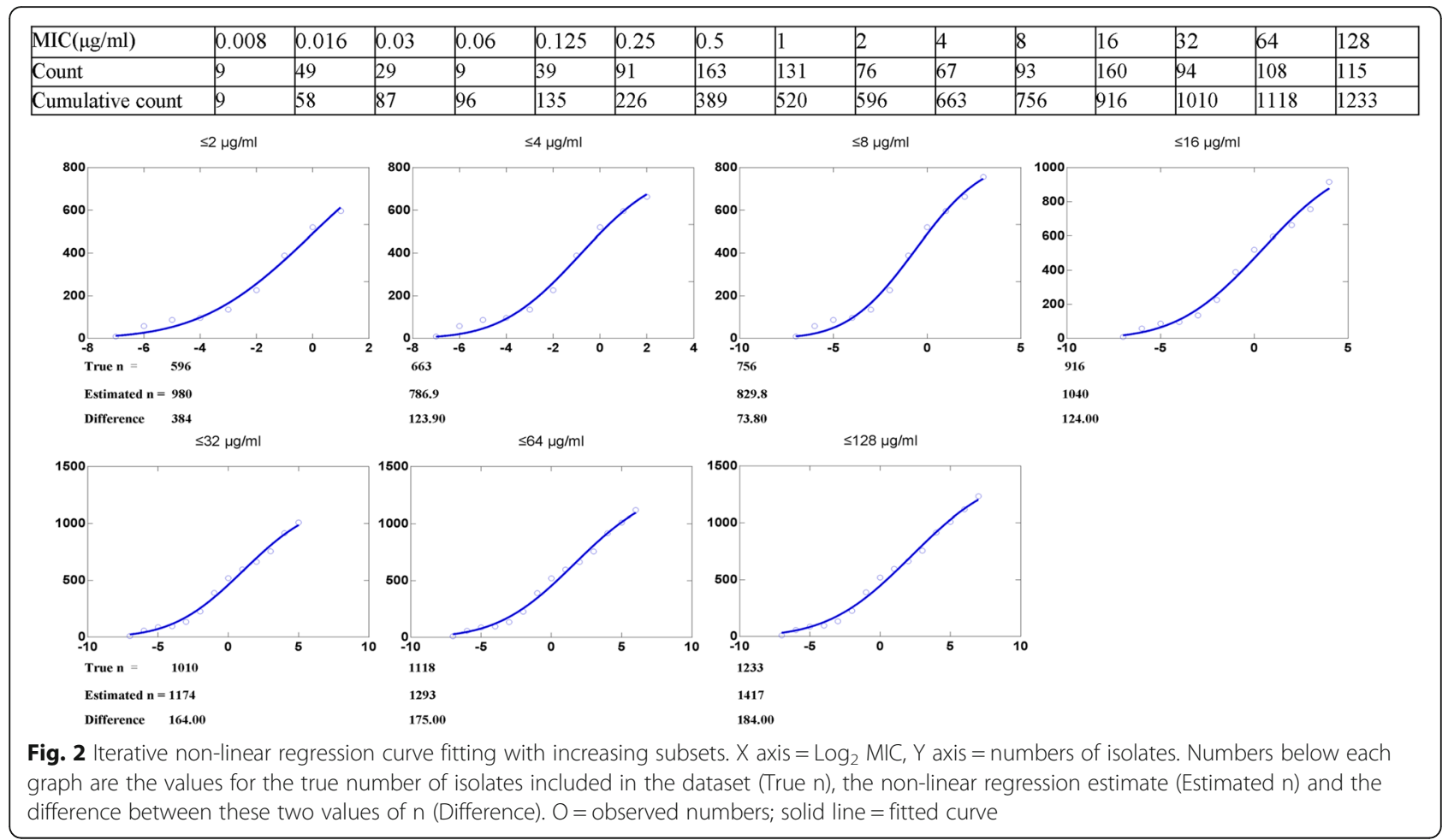

the E. coli isolates with an MIC of $\leq 1.0 \mu \mathrm{g} / \mathrm{ml}$ [25]. While, in our study, $50.82 \%$ of the E. coli isolates $(n=$ 1233) with MIC $>1.0 \mu \mathrm{g} / \mathrm{ml}$ for DANO, which indicated that temporal and geographic differences could be frequently found on the prevalence of resistance.

Susceptibility breakpoints of quinolones and fluoroquinolones (ciprofloxacin, levofloxacin, cinoxacin, enoxacin, gatifloxacin, gemifloxacin, grepafloxacin, lomefloxacin, nalidixic acid, norfloxacin, ofloxacin, and fleroxacin) for Enterobacteriaceae have been established. CLSI [16] recommendations for testing human pathogens against fluoroquinolone, but few guidelines are available for the interpretation of veterinary MIC data. ECV can be used as the most sensitive measurement of the emergence of

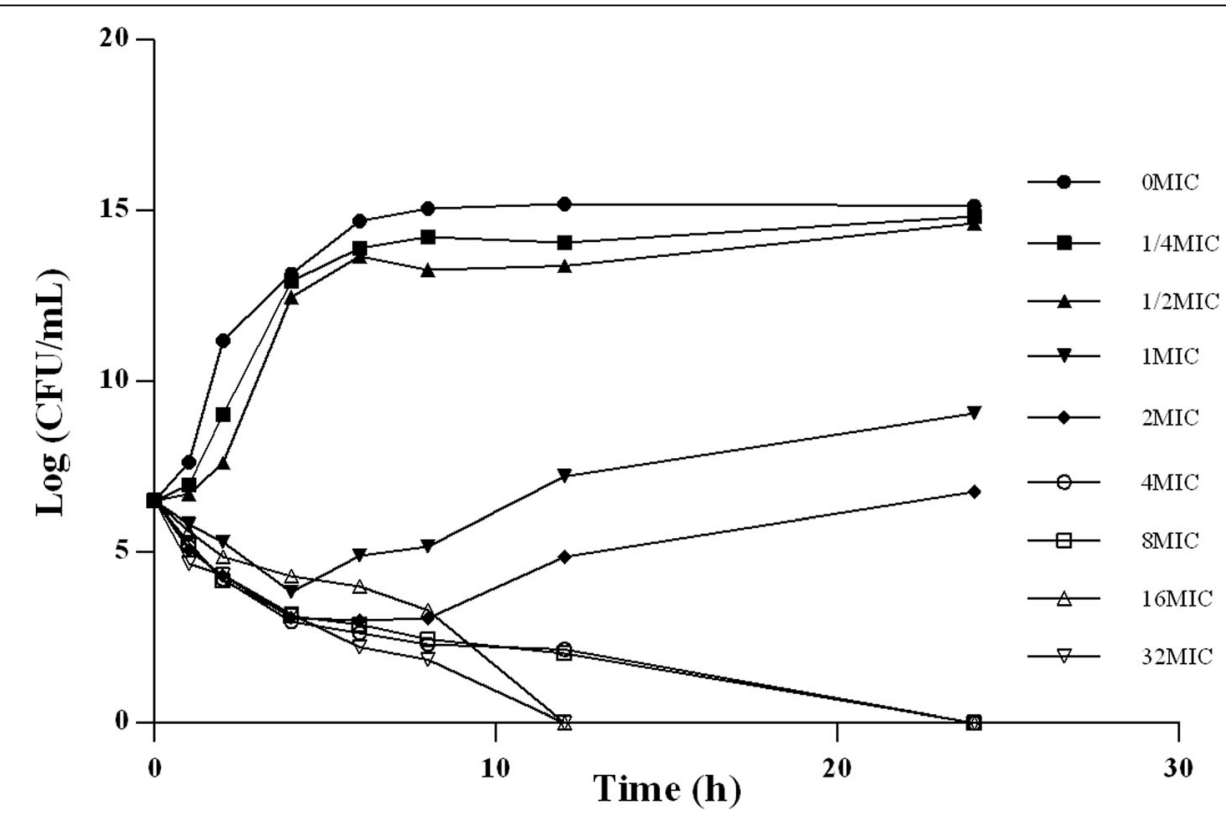

Fig. 3 The in vitro time killing curve of danofloxacin against E.coli 


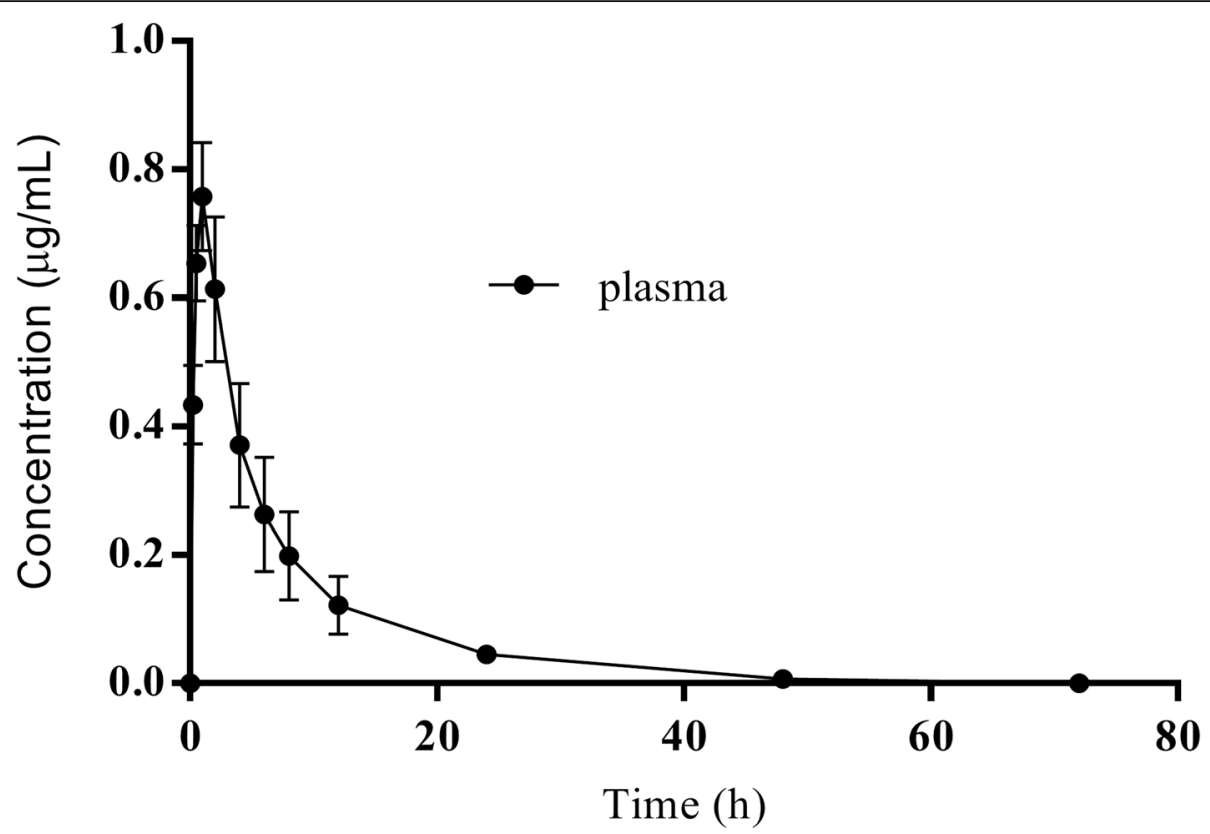

Fig. 4 Concentration-time plot of plasma danofloxacin data at $0,0.25,0.5,1,2,4,6,8,12,24,48$, and $72 \mathrm{~h}$ after i.m. administration at a dose rate of $2.5 \mathrm{mg} / \mathrm{kg}$ in pigs. Values are means $\pm \mathrm{SD}(n=6)$

strains with decreased susceptibility to a given compound when compared with the WT population. These non-WT strains may exhibit one or more acquired resistance mechanisms [26]. Several methods have been reported for determination of ECVs. For instance, Arendrup et al. estimated ECVs as 2-fold dilution steps higher than the $\mathrm{MIC}_{50}$ [27], Rodriguez-Tudela et al. estimated them as 2-fold dilutions above the modal MIC [28], and Kronvall and Turnidge et al. calculated ECVs by statistical methods $[17,18]$. We used nonlinear least squares regression analysis reported in the CLSI methodology to determine ECVs. Finally, the ECV of E.coli for DANO was defined as $8 \mu \mathrm{g} / \mathrm{mL}$ according to the preliminary MIC distribution in our study.

Several studies have established pharmacokinetic data for DANO in a number of farm animal species, including cattle, sheep, goat, chicken and pig [23, 29-32]. The difference in pharmacokinetic parameters between different studies may be due to different breeds or individual differences in pigs. In this study, after i.m. administration of DANO at a dose of $2.5 \mathrm{mg} / \mathrm{kg}$ body weight in pigs, the time to reach to maximum concentration $\left(\mathrm{T}_{\max }\right)$ was 0.97 $\pm 0.08 \mathrm{~h}$, similar to $1 \mathrm{~h}$ as reported by Mann and Frame, but different from $0.64 \mathrm{~h}$ as described by Wang et al.; the peak drug concentration $\left(C_{\max }\right)$ was $0.76 \pm 0.08 \mu \mathrm{g} / \mathrm{mL}$, higher than $0.45 \pm 0.09 \mu \mathrm{g} / \mathrm{mL}$, and was half of $1.5 \mu \mathrm{g} / \mathrm{mL}$ reported by Rottboll and Friis which dosing $5.0 \mathrm{mg} / \mathrm{kg}$; the area under the curve by $24 \mathrm{~h}\left(\mathrm{AUC}_{24}\right)$ was $5.25 \pm 1.35$ $\mathrm{h} \bullet \mu \mathrm{g} / \mathrm{ml}$, higher than $3.34 \pm 0.43 \mathrm{~h} \bullet \mu \mathrm{g} / \mathrm{ml}$ as reported by Wang et al. [10, 31, 33].
From a pharmacodynamic point of view, fluoroquinolones are considered concentration-dependent rather than time-dependent [34]. The in vitro time kill test in our study demonstrated that DANO is also concentration dependent. Thus, the ratios of peak concentration or AUC with the MIC were reported as important determinants of the antibacterial effect of fluoroquinolones in vitro and the ratio of $\mathrm{AUC}_{24} / \mathrm{MIC}$ or $\mathrm{C}_{\max } / \mathrm{MIC}$ were generally used for PK/PD modeling [21, 35].

The parameters $\mathrm{C}_{\max } / \mathrm{MIC}$ and $\mathrm{AUC}_{24} / \mathrm{MIC}$ correlate well with therapeutic outcome. A correlation of these composite parameters to the efficacy of an antibacterial revealed that for fluoroquinolones an $\mathrm{AUC}_{0-24} / \mathrm{MIC}$ of $\geq 125$ is predictive of favorable clinical outcome for Gram negative bacteria [21]. The probability of DANO attaining an AUC: MIC ratio of at least 125 is $92.25 \%$. Therefore, the $\mathrm{CO}_{\mathrm{PD}}$ was defined at $0.03 \mu \mathrm{g} / \mathrm{mL}$.

To the best of our knowledge, this is the first study to establish the ECV and $\mathrm{CO}_{\mathrm{PD}}$ of DANO against E.coli by statistical method. The $\mathrm{CO}_{\mathrm{PD}}(0.03 \mu \mathrm{g} / \mathrm{mL})$ was much lower than the ECV $(8 \mu \mathrm{g} / \mathrm{mL})$ established in our study, implying that the lower $\mathrm{CO}_{\mathrm{PD}}$ in our study may be due to the lower dose of drug administration to pigs, because previous studies concluded that the dose of drug administration may affect the PK-PD breakpoint [36-38]. This suggests that (i) more dosing regimens need to be designed in future investigation; (ii) Further studies are needed to illustrate the relationship between DANO non-WT values proposed in this study and its resistant molecular mechanisms. 
Table 2 PK parameters for danofloxacin in pig plasma after i.m. administration at a dose of $2.5 \mathrm{mg} / \mathrm{kg}(n=6)$

\begin{tabular}{|c|c|c|}
\hline PK parameter & Unit & Mean \pm SD \\
\hline$A$ & $\mu \mathrm{g} / \mathrm{mL}$ & $2.09 \pm 1.46$ \\
\hline B & $\mu \mathrm{g} / \mathrm{mL}$ & $0.41 \pm 0.17$ \\
\hline$a$ & $1 / \mathrm{h}$ & $0.81 \pm 0.41$ \\
\hline$\beta$ & $1 / \mathrm{h}$ & $0.10 \pm 0.02$ \\
\hline $\mathrm{K}_{\mathrm{a}}$ & $1 / \mathrm{h}$ & $2.00 \pm 0.51$ \\
\hline $\mathrm{K}_{10}$ & $1 / \mathrm{h}$ & $0.25 \pm 0.08$ \\
\hline $\mathrm{K}_{12}$ & $1 / \mathrm{h}$ & $0.32 \pm 0.20$ \\
\hline $\mathrm{K}_{21}$ & $1 / \mathrm{h}$ & $0.34 \pm 0.23$ \\
\hline $\mathrm{T}_{1 / 2 \mathrm{Ka}}$ & $\mathrm{h}$ & $0.37 \pm 0.09$ \\
\hline $\mathrm{T}_{1 / 2 \mathrm{a}}$ & $\mathrm{h}$ & $1.07 \pm 0.60$ \\
\hline $\mathrm{T}_{1 / 2 \beta}$ & $\mathrm{h}$ & $7.28 \pm 1.10$ \\
\hline AUC & $\mathrm{h}^{*} \mathrm{\mu g} / \mathrm{mL}$ & $5.25 \pm 1.35$ \\
\hline$T_{\max }$ & $\mathrm{h}$ & $0.97 \pm 0.08$ \\
\hline$C_{\max }$ & $\mu \mathrm{g} / \mathrm{mL}$ & $0.76 \pm 0.08$ \\
\hline $\mathrm{CL}$ & $L / h$ & $7.75 \pm 1.74$ \\
\hline$V_{c}$ & liter/kg & $2.28 \pm 0.39$ \\
\hline$V_{p}$ & liter $/ \mathrm{kg}$ & $2.16 \pm 0.86$ \\
\hline$V_{s s}$ & liter $/ \mathrm{kg}$ & $4.17 \pm 0.76$ \\
\hline
\end{tabular}

$A$ and $B: Y$-axis intercept terms; $\alpha$ : distribution rate constant; $\beta$ : elimination rate constant; $K_{a}$ : absorption rate constant; $K_{10}$ : central compartment elimination rate constant; $\mathrm{K}_{12}$ : rate constant from central to peripheral compartment; $\mathrm{K}_{21}$ : rate constant from peripheral to central compartment; $\mathrm{T}_{1 / 2 \mathrm{Ka}}$ : absorption halflife of the drug; $T_{1 / 2 a}$ : distribution half-life of the drug; $T_{1 / 22}$ : elimination halflife of the drug; AUC: area under the curve of plasma concentration-time; $T_{\text {max: }}$ the time point of maximum plasma concentration of the drug; $C_{\max }$ : the maximum plasma concentration; $\mathrm{CL}$ : body clearance; $\mathrm{V}_{\mathrm{c}}$ : volume of distribution in the central compartment; $\mathrm{V}_{\mathrm{p}}$ : volume of distribution; $\mathrm{V}_{\mathrm{ss}}$ : volume of distribution at steady state

\section{Conclusions}

Compared to the $\mathrm{CO}_{\mathrm{PD}}$ of DANO against E.coli $(0.03 \mu \mathrm{g} / \mathrm{mL})$, the ECV for E.coli seemed reasonable to be used as the final breakpoint of DANO against E.coli in pigs. Therefore, the ECV $(\mathrm{MIC} \leq 8 \mu \mathrm{g} / \mathrm{mL})$ was finally selected as the optimum DANO susceptibility breakpoint for swine E.coli, which could provide a criterion for DANO susceptibility testing and improve prudent use of DANO for protecting public health.

\section{Methods \\ Isolates}

The rectal/cloacal swabs collected on each farm from the pigs were pooled and tested as one analytical sample. Between July 2014 and March 2017, a total of 864 rectal/cloacal swabs of pig were collected in Heilongjiang $(n=297)$, Jilin $(n=151)$, Liaoning $(n=240)$, Henan $(n=97)$, Shandong $(n=30)$, Hubei $(n=20)$, and Yunnan $(n=29)$ provinces of China. In order to isolate E. coli, swabs were streaked out on MacConkey agar plates (Qingdao Hope Bio-Technology Co., Ltd., Qingdao, China) and incubated at $37^{\circ} \mathrm{C}$ for 18 to $24 \mathrm{~h}$. The putative $E$. coli isolates on MacConkey agar (bright pink with a dimple) per sample were transferred to eosin methylene blue agar (Qingdao Hope Bio-Technology Co., Ltd., Qingdao, China) for further purification and were incubated at $37^{\circ} \mathrm{C}$ for 18 to $24 \mathrm{~h}$. One colony with typical $E$. coli morphology was selected from each sample and identified by conventional biochemical methods according to 'Bergey's Manual of Determinative Bacteriology'. In addition, a total of 372 E.coli strains were respectively donated by National Key Laboratory of Veterinary Biotechnology, Harbin Veterinary Research Institute, Chinese Academy of Agricultural Sciences $(n=108)$, Husbandry and Veterinary College, Jilin University $(n=112)$, and College of Animal Husbandry and Veterinary Science, Henan

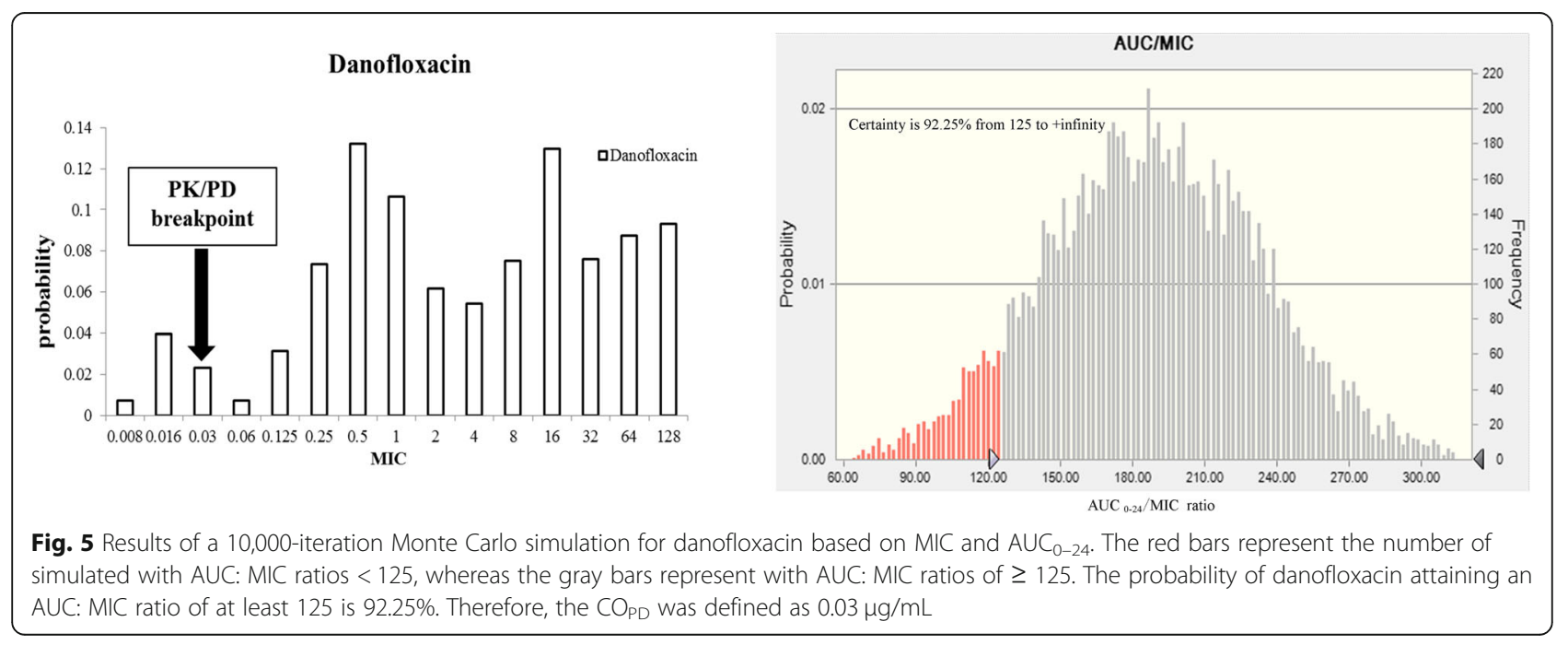


Agricultural University ( $n=152)$. All of the bacterial isolates were confirmed by polymerase chain reaction (PCR) [39].

\section{Antibacterial susceptibility testing}

Broth microdilution testing was performed in accordance with the guidelines in CLSI document M07-A9 [40] at the following laboratories: Department of Microbiology, Department of Pharmacology and Toxicology, and Pharmacy Department in Northeast Agricultural University, Harbin, China. Pure powder of DANO (Qingdao Hope Bio-Technology Co., Ltd., Qingdao, China) was dissolved in ultrapure water to prepare stock solutions of $5120 \mu \mathrm{g} / \mathrm{mL}$. Two-fold serial drug dilutions were prepared in broth (Qingdao Hope Bio-Technology Co., Ltd., Qingdao, China) to achieve the final concentration ranged from 0.008 to $128 \mu \mathrm{g} / \mathrm{mL}$. Each well contains approximately $5 \times 10^{5} \mathrm{CFU} / \mathrm{mL}$ E.coli and cultured in 96 well plates. Plates were incubated at $37^{\circ} \mathrm{C}$ for $20 \mathrm{~h}$. Quality control (QC) isolate E.coli ATCC 25922 was used on each day of testing by the participating laboratories, as recommended by CLSI [40]. Only those results, for which the QC MICs were within the established reference range, were used in the study. The MIC is the lowest concentration of antimicrobial agent that completely inhibits growth of the organism in the microdilution wells as detected by the unaided eye. All MIC determinations were performed in triplicate.

\section{Definitions}

The ECV (also known as the wild-type cutoff, or $\mathrm{CO}_{\mathrm{WT}}$ ), defined as the highest susceptibility endpoint of the wild-type (WT) population MIC, has been shown to detect the emergence of in vitro resistance or to separate WT isolates (without known mechanisms of resistance) from non-WT isolates (with mechanisms of resistance and reduced susceptibilities to the antibacterial agent being evaluated) $[26,41]$. ECVs are calculated by taking into account the MIC distribution, the modal MIC of each distribution, and the inherent variability of the test (usually within one doubling dilution) and should encompass $\geq 95 \%$ of isolates [17].

\section{Analysis}

To analyze the MIC distributions, MICs were transformed into $\log _{2}$ values. The skewness and kurtosis of each MIC distribution were determined. Skewness quantifies the degree of symmetry of the distribution, whereas kurtosis quantifies the extent to which the shape of the data distribution matches the normal distribution. To confirm the presence of more than one MIC distribution, frequency distributions of MIC data were analyzed by nonlinear least squares regression analysis based on the following Cumulative Gaussian Counts equation:Z
$=(X-$ Mean $) / S D, \mathrm{Y}=\mathrm{N} * \mathrm{Zdist}(z)$, in which the Mean is the average of the original distribution, from which the frequency distribution was created; SD is the standard deviation of the original distribution (calculations were performed using Prism 6.0 software, San Diego, CA). Three parameters were estimated, the mean and SD (both $\log _{2}$ ), and the total number $(\mathrm{N})$ in the presumed unimodal distribution. $\mathrm{N}$ was estimated rather than taken as a constant in the regression, because of the desire to fit the data to the distribution without assuming that $\mathrm{N}$ truly contained only wild-type isolates $[17,42]$.

\section{In vitro time-kill studies}

In vitro time-kill studies were conducted in Mueller-Hinton broth with concentrations of DANO ranging from $1 / 4$ to 32 times of the MICs for E.coli JLP95 $\left(\mathrm{O}_{8}\right)$, which were tested separately. The initial inoculum sizes of the bacteria used to generate the time-kill profiles were approximately $10^{6} \mathrm{CFU} / \mathrm{mL} .1 .2 \mathrm{~mL}$ of co-culture was removed from each tube and then $200 \mu \mathrm{L}$ of co-culture was continuously diluted with $1.8 \mathrm{~mL}$ Mueller-Hinton broth to measure the CFU at $0,1,2,4,6,8,12$ and $24 \mathrm{~h}$ following inoculation.

\section{Animals}

Six 5-months-old healthy fragrance pigs weighing 14-16 kg were donated from Clinical Surgery Department's pig breeding farm of Northeast Agricultural University for free use. All animals were provided with a drug-free commercial diet to acclimatize for 1 week prior to the study. After the trial, all animals were returned to them for further feeding and used for subsequent laparoscopic trials. All experimental work was performed in accordance with the animal ethics guidelines approved by the animal care and ethics committee of Northeast Agricultural University (Heilongjiang Province PR China).

\section{Pharmacokinetic study}

DANO (purity > 99\%) was obtained from Zhejiang Guobang Pharmaceutical Company Limited, China. The pure reference standard of DANO was obtained from the Sigma-Aldrich (China).

DANO was intramuscularly injected at $2.5 \mathrm{mg}$ DANO/ $\mathrm{kg}$ body weight in each pig. Blood samples $(5 \mathrm{~mL})$ from the brachiocephalic vein were collected into EDTA dipotassium salt tubes at $0.15,0.5,1,2,4,6,8,12,24,48$ and $72 \mathrm{~h}$ after injection. Plasma was separated by centrifugation at $3000 \mathrm{~g}$ for $10 \mathrm{~min}$ and stored at $-20^{\circ} \mathrm{C}$ until analysis.

The method for the analysis of DANO concentration in plasma was modified from that described by [43, 44]. The HPLC system Waters 2695 was connected to a Waters 2475 fluorescence detector $(\lambda \mathrm{ex}=280 \mathrm{~nm}$ and $\lambda \mathrm{em}$ $=450 \mathrm{~nm}$ ) with a mixture of acetonitrile and aqueous 
solution $(15: 85, v / \mathrm{v})$ as the mobile phase. The aqueous solutions were prepared by dissolving potassium dihydrogenophosphate $(0.020 \mathrm{M})$, phosphoric acid $(0.006 \mathrm{M})$, and tetraethylammonium bromide $(0.012 \mathrm{M})$ in water. The $\mathrm{pH}$ of the mobile phase was adjusted to 3.0 by addition of $2 \mathrm{~N} \mathrm{NaOH}$. The flow rate was set at 1.0 $\mathrm{mL} / \mathrm{min}$; A Waters $\mathrm{C}_{18}$ reverse phase column $\mathrm{C}_{18}$ $(250 \mathrm{~mm} \times 4.6 \mathrm{~mm}$ I.D.; particle size, $5 \mu \mathrm{m})$ was used to perform $\mathrm{HPLC}$ at $30^{\circ} \mathrm{C}$; and the injection volume was $10 \mu \mathrm{L}$.

Samples were thawed at room temperature, and $10 \mu \mathrm{L}$ of $50 \mu \mathrm{g} / \mathrm{mL}$ ciprofloxacin (Sigma-Aldrich) was added to plasma $(0.5 \mathrm{~mL})$ as the internal standard. After adding 3 $\mathrm{mL}$ of acetonitrile, the mixed samples were shaken at 220 oscillations/min for $15 \mathrm{~min}$ and then centrifuged at $12000 \mathrm{~g}$ for $10 \mathrm{~min}$. The organic layer was transferred into a sterilized tube and dried at $40^{\circ} \mathrm{C}$ under nitrogen stream. The residue was dissolved in the mobile phase $(0.5 \mathrm{~mL})$, and $10 \mu \mathrm{L}$ injected for HPLC analysis.

The limit of detection (LOD) was $0.005 \mu \mathrm{g} / \mathrm{mL}$ and the limit of quantification (LOQ) was $0.01 \mu \mathrm{g} / \mathrm{mL}$ in plasma, respectively. Standard curves were linear from 0.01 to $1.5 \mu \mathrm{g} / \mathrm{mL}$ in plasma $\left(R^{2}=0.9999\right)$. The inter-day variation for determination in plasma ranged from 0.18 to $1.50 \%$. The recovery of DANO in plasma ranged from $85.80 \pm 0.16 \%$ to $103.40 \pm 4.89 \%$.

\section{Pharmacokinetic analysis}

PK analysis was conducted by using WinNonlin v.5.2.1 (Pharsight Corporation, Mountain View, CA, USA). Mininmum Akaike Information Criteria Estimates (MAICE) was applied to determine the best fit of model for each pig [45].

\section{Monte Carlo analysis}

A 10,000-subject Monte Carlo simulation was conducted for each drug at each of the following MIC: 0.008, 0.016, $0.03,0.06,0.03,0.5,1,2,4,8,16,32,64$ and $128 \mu \mathrm{g} / \mathrm{mL}$ using ORACLE CRYSTAL BALL software (version 11.1; Oracle USA, Denver, CO, USA). Based on pharmacokinetic results of DANO in pigs in this study, a conservative $\mathrm{PK} / \mathrm{PD}$ value $\left(\mathrm{AUC}_{0-24} / \mathrm{MIC}=125\right)$ was selected to calculate the PTA [21]. $\mathrm{AUC}_{0-24}$ was not measured for the fluoroquinolones, it was calculated as follows: $A C_{0-24}=$ Dose $/ V_{s s} \times K_{d}$, where $V_{s s}$ was the volume of distribution at steady state $(\mathrm{L} / \mathrm{kg})$ and $\mathrm{K}_{\mathrm{d}}$ the elimination rate constant $\left(\mathrm{h}^{-1}\right)$ [20]. $\mathrm{AUC}_{0-24}$ was assumed to be log-normally distributed, and the PK/PD indices were calculated for each simulated subject. The PTA was estimated at each MIC as the probability that at least the target level of the PK/PD index is achieved. The $\mathrm{CO}_{\mathrm{PD}}$ was defined as the highest MIC at which the PTA was $\geq 90 \%[46,47]$.

\section{Abbreviations}

CLSI: Clinical and Laboratory Standards Institute; COpD: Pharmacodynamic cutoff; DANO: Danofloxacin; E.coli: Escherichia coli; ECV: Epidemiologic cutoff value; ETEC: Enterotoxigenic E. coli; MICs: Minimum inhibitory concentrations; PK: Pharmacokinetic; PTA: Probability of target attainment;

PWD: Postweaning diarrhea; WT: Wild type

\section{Acknowledgments}

We would like to thank the following organizations for kindly donating E. coli strains: National Key Laboratory of Veterinary Biotechnology, Harbin Veterinary Research Institute, Chinese Academy of Agricultural Sciences; Husbandry and Veterinary College, Jilin University; and College of Animal Husbandry and Veterinary Science, Henan Agricultural University.

\section{Funding}

This study was funded by the National Science and Technology Project and National 13th Five-Year Science and Technology Project (prevention and control of major epidemics and comprehensive research and development of safe and efficient aquaculture of livestock and poultry, 2016YFD0501302). The funders had no role in the design of the study and collection, analysis and interpretation of data and in writing the manuscript.

\section{Availability of data and materials}

The datasets used and analyzed in this study are available from the corresponding author on reasonable request.

\section{Authors' contributions}

XZ conceived of the study and participated in its design and coordination and helped to draft the manuscript. YY design the experiment, completed the experiments and draft the manuscript. $Z Y, L, C P, X T, L R$ and $Y H$ help to carried out the bacteria isolation, the MIC determination and in vitro time kill curve studies, IM revised the manuscript. All authors read and approved the final manuscript.

\section{Ethics approval}

All experimental work was performed in accordance with the animal ethics guidelines approved by the animal care and ethics committee of Northeast Agricultural University (Heilongjiang Province PR China).

Consent for publication

Not applicable.

\section{Competing interests}

The authors declare that they have no competing interests.

\section{Publisher's Note}

Springer Nature remains neutral with regard to jurisdictional claims in published maps and institutional affiliations.

Received: 18 September 2018 Accepted: 16 January 2019

Published online: 04 February 2019

\section{References}

1. Roussel C, Sivignon A, de Wiele TV, Blanquet-Diot S. Foodborne enterotoxigenic Escherichia coli: from gut pathogenesis to new preventive strategies involving probiotics. Future Microbiol. 2017;12:73-93.

2. Kotloff KL, Nataro JP, Blackwelder WC, Nasrin D, Farag TH, Panchalingam S, Wu Y, Sow SO, Sur D, Breiman RF, et al. Burden and aetiology of diarrhoeal disease in infants and young children in developing countries (the global enteric multicenter study, GEMS): a prospective, case-control study. Lancet. 2013;382(9888):209-22.

3. Qadri F, Svennerholm AM, Faruque AS, Sack RB. Enterotoxigenic Escherichia coli in developing countries: epidemiology, microbiology, clinical features, treatment, and prevention. Clin Microbiol Rev. 2005;18(3):465-83.

4. Fairbrother JM, Nadeau E, Gyles CL. Escherichia coli in postweaning diarrhea in pigs: an update on bacterial types, pathogenesis, and prevention strategies. Anim Health Res Rev. 2005;6(1):17-39.

5. Terrado-Campos D, Tayeb-Cherif K, Peris-Vicente J, Carda-Broch S, EsteveRomero J. Determination of oxolinic acid, danofloxacin, ciprofloxacin, and enrofloxacin in porcine and bovine meat by micellar liquid chromatography with fluorescence detection. Food Chem. 2017;221:1277-84. 
6. Aliabadi FS, Ali BH, Landoni MF, Lees P. Pharmacokinetics and PK-PD modelling of danofloxacin in camel serum and tissue cage fluids. Vet J. 2003;165(2):104-18.

7. Ouyang W, Xue H, Chen Y, Gao W, Li X, Wei J, Wen Z. Clinical characteristics and antimicrobial patterns in complicated intra-abdominal infections: a 6year epidemiological study in southern China. Int J Antimicrob Agents. 2016;47(3):210-6.

8. CDC. CDC (2014). Best practices for comprehensive tobacco control programs Retrieved from CDC Web site: https://www.cdc.gov/ecoli/etec html. Accessed 26 Jan 2019.

9. Burch DGS, Sperling D. Amoxicillin-current use in swine medicine. J Vet Pharmacol Ther. 2018;41(3):356-68.

10. Wang C, Ai D, Chen C, Lin H, Li J, Shen H, Yi W, Qi Y, Wu H, Cao J. Preparation and evaluation of danofloxacin mesylate microspheres and its pharmacokinetics in pigs. Vet Res Commun. 2009;33(8):1013-22.

11. Marshall BM, Levy SB. Food animals and antimicrobials: impacts on human health. Clin Microbiol Rev. 2011;24(4):718-33.

12. WHO. Antimicrobial resistance: global report on surveillance: World Health Organization; 2014.

13. Xia LN, Tao XQ, Shen JZ, Dai L, Wang Y, Chen X, Wu CM. A survey of betalactamase and 16S rRNA methylase genes among fluoroquinolone-resistant Escherichia coli isolates and their horizontal transmission in Shandong, China. Foodborne Pathog Dis. 2011;8(12):1241-8.

14. Lockhart SR, Ghannoum MA, Alexander BD. Establishment and use of epidemiological cutoff values for molds and yeasts by use of the clinical and laboratory standards institute M57 standard. J Clin Microbiol. 2017;55(5):1262-8.

15. Espinel-Ingroff A, Colombo AL, Cordoba S, Dufresne PJ, Fuller J, Ghannoum M, Gonzalez GM, Guarro J, Kidd SE, Meis JF, et al. International evaluation of MIC distributions and epidemiological cutoff value (ECV) definitions for Fusarium species identified by molecular methods for the CLSI broth microdilution method. Antimicrob Agents Chemother. 2016;60(2):1079-84.

16. CLSI. Performance standards for antimicrobial susceptibility testing: Clinical and Laboratory Standards Institute; 2017.

17. Turnidge J, Kahlmeter G, Kronvall G. Statistical characterisation of bacterial wild-type MIC value distributions and the determination of epidemiological cut-off values. Clin Microbiol Infect. 2006;12(5):418-25.

18. Kronvall G. Normalized resistance interpretation as a tool for establishing epidemiological MIC susceptibility breakpoints. J Clin Microbiol. 2010;48(12): 4445-52.

19. Zhang P, Hao H, Li J, Ahmad I, Cheng G, Chen D, Tao Y, Huang L, Wang Y, Dai $M$, et al. The epidemiologic and Pharmacodynamic cutoff values of Tilmicosin against Haemophilus parasuis. Front Microbiol. 2016;7:385.

20. Frei CR, Wiederhold NP, Burgess DS. Antimicrobial breakpoints for gram-negative aerobic bacteria based on pharmacokineticpharmacodynamic models with Monte Carlo simulation. J Antimicrob Chemother. 2008;61(3):621-8.

21. Andes D, Anon J, Jacobs MR, Craig WA. Application of pharmacokinetics and pharmacodynamics to antimicrobial therapy of respiratory tract infections. Clin Lab Med. 2004:24(2):477-502.

22. Nicolau DP, Ambrose PG. Pharmacodynamic profiling of levofloxacin and gatifloxacin using Monte Carlo simulation for community-acquired isolates of Streptococcus pneumoniae. Am J Med. 2001;111(Suppl 9A):13S-8S discussion 36S-38S

23. Aliabadi FS, Lees P. Pharmacokinetics and pharmacodynamics of danofloxacin in serum and tissue fluids of goats following intravenous and intramuscular administration. Am J Vet Res. 2001;62(12):1979-89.

24. Fabrega A, Sanchez-Cespedes J, Soto S, Vila J. Quinolone resistance in the food chain. Int J Antimicrob Agents. 2008:31(4):307-15.

25. Raemdonck DL, Tanner AC, Tolling ST, Michener SL. In vitro susceptibility of avian Escherichia coli and Pasteurella multocida to danofloxacin and five other antimicrobials. Avian Dis. 1992;36(4):964-7.

26. Turnidge J, Paterson DL. Setting and revising antibacterial susceptibility breakpoints. Clin Microbiol Rev. 2007;20(3):391-408 table of contents.

27. Arendrup MC, Garcia-Effron G, Lass-Florl C, Lopez AG, Rodriguez-Tudela JL, Cuenca-Estrella M, Perlin DS. Echinocandin susceptibility testing of Candida species: comparison of EUCAST EDef 7.1, CLSI M27-A3, Etest, disk diffusion, and agar dilution methods with RPMI and isosensitest media. Antimicrob Agents Chemother. 2010;54(1):426-39.

28. Rodriguez-Tudela JL, Alcazar-Fuoli L, Mellado E, Alastruey-lzquierdo A, Monzon A, Cuenca-Estrella M. Epidemiological cutoffs and cross-resistance to azole drugs in Aspergillus fumigatus. Antimicrob Agents Chemother. 2008;52(7):2468-72.

29. Aliabadi FS, Landoni MF, Lees P. Pharmacokinetics (PK), pharmacodynamics (PD), and PK-PD integration of danofloxacin in sheep biological fluids. Antimicrob Agents Chemother. 2003;47(2):626-35.

30. Friis C. Penetration of danofloxacin into the respiratory tract tissues and secretions in calves. Am J Vet Res. 1993;54(7):1122-7.

31. Mann DD, Frame GM. Pharmacokinetic study of danofloxacin in cattle and swine. Am J Vet Res. 1992:53(6):1022-6.

32. Zeng Z, Deng G, Shen X, Rizwan-Ul-Haq M, Zeng D, Ding H. Plasma and tissue pharmacokinetics of danofloxacin in healthy and in experimentally infected chickens with Pasteurella multocida. J Vet Pharmacol Ther. 2011; 34(1):101-4.

33. Rottboll $L A$, Friis $C$. Microdialysis as a tool for drug quantification in the bronchioles of anaesthetized pigs. Basic Clin Pharmacol Toxicol. 2014; 114(3):226-32.

34. Craig WA. Pharmacokinetic/pharmacodynamic parameters: rationale for antibacterial dosing of mice and men. Clin Infect Dis. 1998;26(1):1-10 quiz 11-12

35. Blaser J, Stone BB, Groner MC, Zinner SH. Comparative study with enoxacin and netilmicin in a pharmacodynamic model to determine importance of ratio of antibiotic peak concentration to MIC for bactericidal activity and emergence of resistance. Antimicrob Agents Chemother. 1987:31(7):1054-60.

36. Hao H, Pan H, Ahmad I, Cheng G, Wang Y, Dai M, Tao Y, Chen D, Peng D, Liu Z, et al. Susceptibility breakpoint for enrofloxacin against swine Salmonella spp. J Clin Microbiol. 2013;51(9):3070-2.

37. Messenger KM, Papich MG, Blikslager AT. Distribution of enrofloxacin and its active metabolite, using an in vivo ultrafiltration sampling technique after the injection of enrofloxacin to pigs. J Vet Pharmacol Ther. 2012;35(5):452-9.

38. Bimazubute M, Cambier C, Baert K, Vanbelle S, Chiap P, Albert A, Delporte $J P$, Gustin P. Penetration of enrofloxacin into the nasal secretions and relationship between nasal secretions and plasma enrofloxacin concentrations after intramuscular administration in healthy pigs. J Vet Pharmacol Ther. 2010:33(2):183-8.

39. Seurinck S, Verstraete W, Siciliano SD. Use of 16S-23S rRNA intergenic space region $P C R$ and repetitive extragenic palindromic PCR analyses of Escherichia coli isolates to identify nonpoint fecal sources. Appl Environ Microbiol. 2003:69(8):4942-50.

40. CLSI. CLSI document M07-A9. Wayne: Clinical and Laboratory Standards Institute; 2012

41. Kahlmeter G, Brown DF, Goldstein FW, MacGowan AP, Mouton JW, Osterlund A, Rodloff A, Steinbakk M, Urbaskova P, Vatopoulos A. European harmonization of MIC breakpoints for antimicrobial susceptibility testing of bacteria. J Antimicrob Chemother. 2003;52(2):145-8.

42. Meletiadis J, Mavridou E, Melchers WJ, Mouton JW, Verweij PE. Epidemiological cutoff values for azoles and Aspergillus fumigatus based on a novel mathematical approach incorporating cyp51A sequence analysis. Antimicrob Agents Chemother. 2012;56(5):2524-9.

43. Garcia MA, Solans C, Aramayona JJ, Rueda S, Bregante MA. Development of a method for the determination of danofloxacin in plasma by HPLC with fluorescence detection. Biomed Chromatogr. 2000;14(2):89-92.

44. Schrickx JA, Fink-Gremmels J. Danofloxacin-mesylate is a substrate for ATPdependent efflux transporters. Br J Pharmacol. 2007;150(4):463-9.

45. Yamaoka K, Nakagawa T, Uno T. Statistical moments in pharmacokinetics. J Pharmacokinet Biopharm. 1978;6(6):547-58.

46. Mouton JW, Dudley MN, Cars O, Derendorf H, Drusano GL. Standardization of pharmacokinetic/pharmacodynamic (PK/PD) terminology for antiinfective drugs: an update. J Antimicrob Chemother. 2005:55(5):601-7.

47. Dudley MN, Ambrose PG. Pharmacodynamics in the study of drug resistance and establishing in vitro susceptibility breakpoints: ready for prime time. Curr Opin Microbiol. 2000;3(5):515-21. 